\title{
Design and Loss Analysis of LCL Filter Inductors for Two-Level and Three-Level Inverters
}

\author{
Ibrahim SEFA, Necmi ALTIN, Saban OZDEMIR \\ Gazi University, Faculty of Technology, Ankara \\ Turkey, isefa@gazi.ed.tr, naltin@gazi.edu.tr, \\ sabanozdemir@gazi.edu.tr
}

\author{
Selami BALCI, M. Baha Bayram \\ Ministry of National Education, Ankara Turkey \\ selamibalci@gmail.com, bahabayram@gmail.com
}

\author{
Hasan KELEBEK \\ ${ }^{3}$ Inform Electronic Industrial Trade Limited Company, Istanbul, Turkey \\ hasan.kelebek@inform.com.tr
}

\begin{abstract}
Grid connected inverters with LCL output filters are widely used in exporting energy generated from renewable energy sources. The LCL filter and inductors used in this filter has important effect on inverter performance. Although it is different in high power levels nowadays, powder cores are commonly used in inductor design in low and medium power levels. In this study, inductors for LCL filter of the gridconnected inverter are designed. The co-simulation studies are performed and performance and losses of the designed filter is analyzed for two-level and three-level inverter topologies. It is seen that, total losses of the LCL filter of three-phase three-level inverter is $\mathbf{3 5 . 9 \%}$ lower than two-level inverter.
\end{abstract}

Keywords - Inductor design, LCL filter, FEA, cosimulation, powder core.

\section{INTRODUCTION}

Grid connected inverters are used to export energy generated by renewable energy sources to the grid. These inverters can be designed with conventional two-level inverter or three-level inverter. Figure 1 shows three-phase two-level and three-level gridconnected inverter circuit with LCL filter. Besides, LCL filters are commonly used in grid connected inverter and PWM rectifier applications with their advantages such as better attenuation rate, lower size and cost. As can be seen from the figure, two different inductors named inverter side and grid side are used in the LCL filters. Besides, high frequency ripple currents flow through inverter side inductor because of PWM switching. In addition, DC current can flow through these inductors in certain amount when the wave symmetry is not good [1-2].

A significant increase in inductor core losses occurs when high frequency ripple current flow through the inductors, and calculation of losses also becomes harder with classical methods before the design phase. The possibility of electromagnetic modeling with the finite element analysis (FEA) method in the modern design concept has brought some innovations in the design procedure of the magnetic circuit elements [3]. Thus, parameters such as flux, force and losses, which are difficult to measure, can be visualized.

Various core materials have been investigated to reduce the losses of inductors used in LCL filters. Sendust core materials which are produced by powder metallurgy technology have been developed in recent years. These cores are preferred in product designs in compact structures where the gap is required and low losses are desired even under high frequency and magnetic saturation is undesirable [4-5].

When the powder core material is used as the high frequency LCL filter inductor in the two-level inverter circuit, the inductance stability is obtained and the core losses are reduced [6]. In recent years, with the increasing availability of powder core materials (such as EE and block core) for large power applications, significant advantages have been achieved in terms of core losses when high frequency DC inductor and AC inductor designs are made. However, for inductors used in PFC circuits, it provides very satisfactory benefits both in terms of inductance stability and efficiency [7-9].

The switching frequency is limited due to the silicon-based switches in two-level inverters, so that the three-level topologies have become common at medium and high powers. Although many studies have been presented on switching and transmission losses of two-level and three-level inverter schemes, studies on filter losses, which are effective on cost and size of inverter designs, are very few.

In this study, inductors for LCL filter of the inverter which has $16 \mathrm{kVA}$ output power and $10 \mathrm{kHz}$ switching frequency are designed. Designed inductors are tested for both two-level and three-phase threelevel inverters, and LCL filter losses and efficiency values are analyzed and compared. Additionally, the results obtained with finite element analysis (FEA) have been reported. The inverter circuits were designed in the Ansys-Electronics Desktop 18.0Simplorer software and inductors were modeled in Maxwell 3D software. Both Simplorer and Maxwell software were executed interactively together in order 
to determine inverter circuit parameters and inductor magnetic parameters.

\section{TWO-LEVEL AND THREE-LEVEL CONVERTERS}

High power grid interactive inverters are usually designed with three-level inverter topologies. However, in the case of small to medium power range conventional two-level topology still an alternative to three-level topologies. The DC link voltage, inverter power and cost are considered while the inverter topology has been determined. Wide band gap device $\mathrm{SiC}$ also affects the decision of topology. In this study, designed inductors are tested with two-level and threelevel inverter circuits which have same power level and switching frequency. Inductors are designed in Ansys Maxwell and linked to Simplorer software where power electronics circuits and PWM generation is processed. Thus, core losses, winding losses are seen in a realistic working conditions and compared for two-level and three-level inerter topologies given in Fig.1.

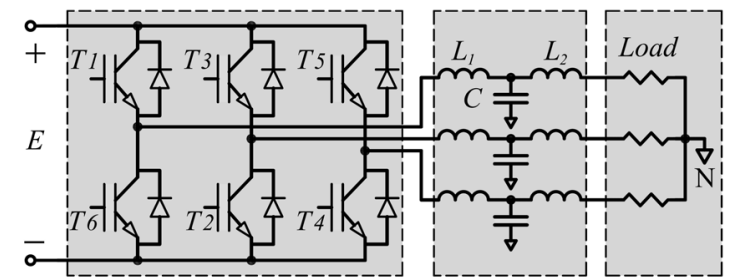

(a)

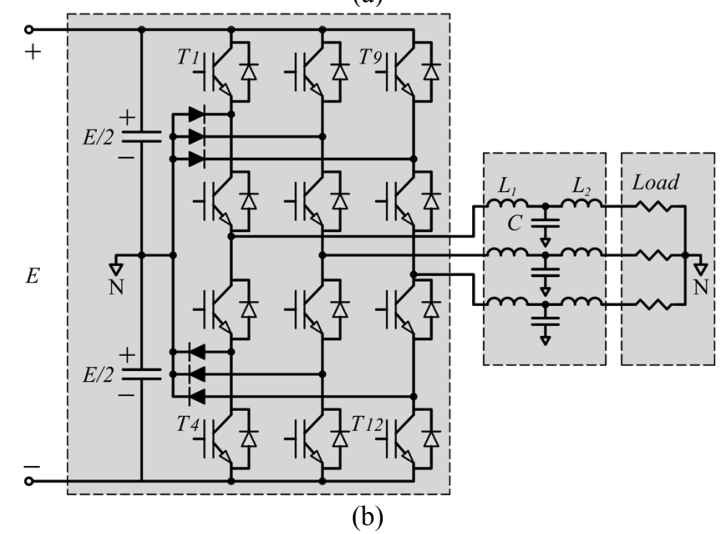

Figure 1. Inverter topologies, a) Two-level inverter, b) Three-level NPC inverter

\section{DESIGNING PARAMETERS OF THE INDUCTOR}

Inductor currents consist of high frequency components in high frequency converter applications. The inductance value directly affects the ripple amplitude in the design of the inductors used in high frequency power electronic circuits. The average value of the load current also affects the electrical properties of the design. Therefore, design of the inductor is important. There are two very useful methods in the inductor design, such as the core geometrical parameter (which is based on the mathematical product of the window region and the core section) $\left(\mathrm{A}_{\mathrm{p}}\right)$ method and the core geometry coefficient $\left(\mathrm{K}_{\mathrm{g}}\right)$ method which is determined according to the $5 \%$ regulation principle [10-11]. Inductors are designed to provide the required inductance value according to a certain frequency and AC amplitude. Desired inductance value of the inductor is necessary condition. The stability of the inductance value over the working area, limitations depending of the saturation, size, efficiency and cost are most important parameters of the design and affect each other. In addition, amplitude of the ripple and ripple frequency produce losses, thus increases the heat of the inductor. Furthermore, the stability of the obtained inductance value throughout the entire operating range is tested by AC currents parametrically [12].

Thus, under requirements and constraints, the inductor design process includes the steps of determining the magnetic core material according to the operating frequency value, determining the shape of the core and its dimensions, determination of number of turns and determination of winding crosssection area steps [10-11].

Contrary to core designs with gap, core materials with distributed gap like Kool $\mathrm{Mu}$ makes the saturation softer and prevents hard falls [3-5]. A soft reduction in the inductance value of the inductor designed with powder core material is observed at the parametric inductance graph shown in Fig.2.

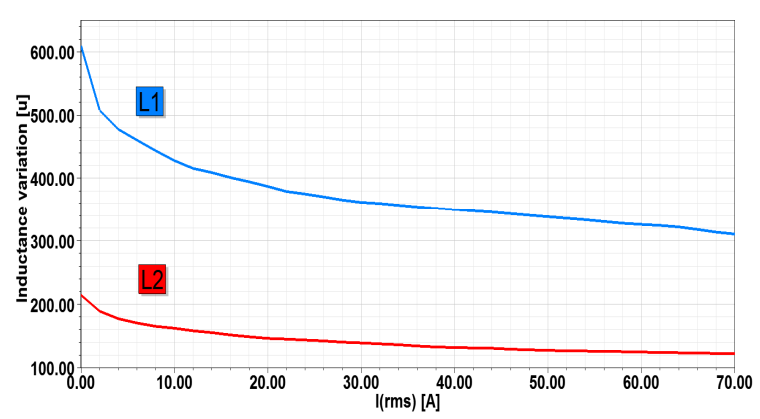

Figure 2. Parametric inductance variations of $\mathrm{L}_{1} \& \mathrm{~L}_{2}$ depending on AC excitation

\section{MOdELING AND SIMULATION STUdIES}

The inductors of $200 \mathrm{uH}$ and $600 \mathrm{uH}$ designed for the LCL filter circuit used at the inverter output are modeled in three dimensions. Then the electromagnetic equivalent of these inductors is defined by the link given to the power electronic circuit. The inverter circuit parameters used in the simulations are shown in Table I. Two- and three-level inverter circuits are simulated at the same load and are given comparatively in this section. In addition, the losses of the inductors with FEA were determined and the filtering capabilities were tested and compared. These comparisons ripple value of the voltage waveform obtained at the output LCL filter, core losses, as many windings losses and flux distribution parameter is determined.

\section{A. Design Steps of the Inductors}

\section{Step: Sizing of the inductor core}

Peak value of the current ( $\mathrm{I}_{\text {Lmax) }}$ flowing through the inductor is obtained by adding half of the ripple current amplitude $(\Delta \mathrm{I} / 2)$ to the peak value of the current $\left(I_{\max }\right)$ as given in (1):

$$
I_{L \max }=I_{\max }+\frac{\Delta I}{2}=33.08+\frac{4.68}{2}=35.4 \mathrm{~A}
$$


Thus, energy stored in inductor (W) which is used to calculate basic mechanical parameters and sizing of the inductor can be obtained by using (2):

$$
W=\frac{1}{2} L I_{L \max }^{2}=\frac{1}{2} 600 \cdot 10^{-6} \times 35.4^{2}=0.37 j
$$

TABLE I. PARAmeters of The Simulation Circuit

\begin{tabular}{|l|l|}
\hline Parameter & Value \\
\hline Output power & $16 \mathrm{kVA}$ \\
\hline DC link voltage & $780 \mathrm{~V}$ \\
\hline Phase current & $23.4 \mathrm{~A}(\mathrm{rms})$ \\
\hline Load type & Resistive-10 $\Omega /$ phase \\
\hline PWM switching frequency & $10 \mathrm{kHz}$ \\
\hline AC voltage frequency & $50 \mathrm{~Hz}$ \\
\hline Modulation Ratio & 0.83 \\
\hline Number of pulses & 200 \\
\hline Inverter output voltage & $230 \mathrm{~V}(\mathrm{rms})($ phase voltage $)$ \\
\hline LCL capacitor & $20 \mu \mathrm{F}-18 \mathrm{~m} \Omega$ ESR-400 V AC \\
\hline LCL inductor & $600 \mu \mathrm{H} / 200 \mu \mathrm{H}\left(\mathrm{L}_{1} / \mathrm{L}_{2}\right)$ \\
\hline Core type & $2 \times \mathrm{EE} 8020$ \\
\hline Core material & $\mathrm{Kool} \mathrm{Mu} \mathrm{powder} \mathrm{core} 26 \mu$ \\
\hline Winding type and material & $48 \mathrm{x} 0.3 \mathrm{~mm} \mathrm{Cu} \mathrm{foil}$ \\
\hline Co-simulation time period & $100 \mathrm{~ms}$ \\
\hline Co-simulation time steps & $1 \mu \mathrm{s} / 10 \mu \mathrm{s}(\mathrm{min} / \mathrm{max})$ \\
\hline
\end{tabular}

The basic mechanical parameter $\left(\mathrm{A}_{\mathrm{p}}\right)$ in inductor sizing is determined with (3) by using technical specifications given in Table I. Since saturation flux density will differ with the core material type, here core material type may cause a difference in inductor core sizing.

$$
A_{p}=\frac{2 W 10^{4}}{K_{u} J_{\max } B_{m}}=\frac{2 \times 0.37 \times 10^{4}}{0.7 \times 2.5 \times 10^{2} \times 0.5}=84.5 \mathrm{~cm}^{4}
$$

where, window utilization constant $\left(\mathrm{K}_{\mathrm{u}}\right)$ is used 0.7 , current density is used as $2.5 \mathrm{~A} / \mathrm{mm}^{2}$ and the flux density is used as $0.5 \mathrm{~T}$.

\section{Step: Determining cross section of the inductor winding}

Cross section of the inductor $\left(A_{w}\right)$ is determined according to the maximum current value of the inductor by using (4):

$$
A_{w}=\frac{I_{L \max }}{J_{\max }}=\frac{35.4}{2.5}=14.1 \mathrm{~mm}^{2}
$$

The $C u$ foil with dimensions of $48 \times 0.3 \mathrm{~mm}$ is sufficient for this inductor design.

\section{Step: Determining core cross-sectional area and window area}

Window area $\left(\mathrm{W}_{\mathrm{a}}\right)$ can be easily calculated by using standard dimensions [13] of the EE8020 core by using (5):

$$
W_{a}=1.945 \times 5.7=11.1 \mathrm{~cm}^{2}
$$

The core cross-sectional are $\left(\mathrm{A}_{\mathrm{c}}\right)$ can be calculated by using $(6)$, basic mechanical parameter of the core $\left(A_{p}\right)$ and window area $\left(\mathrm{W}_{\mathrm{a}}\right)$ :

$$
A_{c}=\frac{A_{p}}{W_{a}}=\frac{84.5}{11.1}=7.62 \mathrm{~cm}^{2}
$$

Thus, number of core can be obtained by assuming the effective core cross-sectional area of the EE8020 core as $3.89 \mathrm{~cm}^{2}$ [13].

$$
n=\frac{A_{\mathcal{C}}}{3.89}=\frac{7.62}{3.89} \cong 2
$$

\section{B. FEA Co-Simulation Metodology}

Simulations have been carried out according to the steps given in the flowchart depicted in Fig. 3. Thus, the behavior of the inductors can be tested in the power electronics circuit [14]. The $\mathrm{L}_{1}$ and $\mathrm{L}_{2}$ inductors of the LCL filter are modelled and designed in AnsysMaxwell software were linked to Simplorer software for co-simulation [6], and both power electronic circuit modeled in Simplorer and magnetic circuit AnsysMaxwell are simulated simultaneously. The simulation circuit is given in Fig. 4. In this simulation, the individual losses of each of the filter inductors are calculated. In addition, foil winding losses of the inductors are also obtained. The core and winding losses were determined from the Maxwell software and its transient analysis solver, and the obtained results were reported in the Table II.

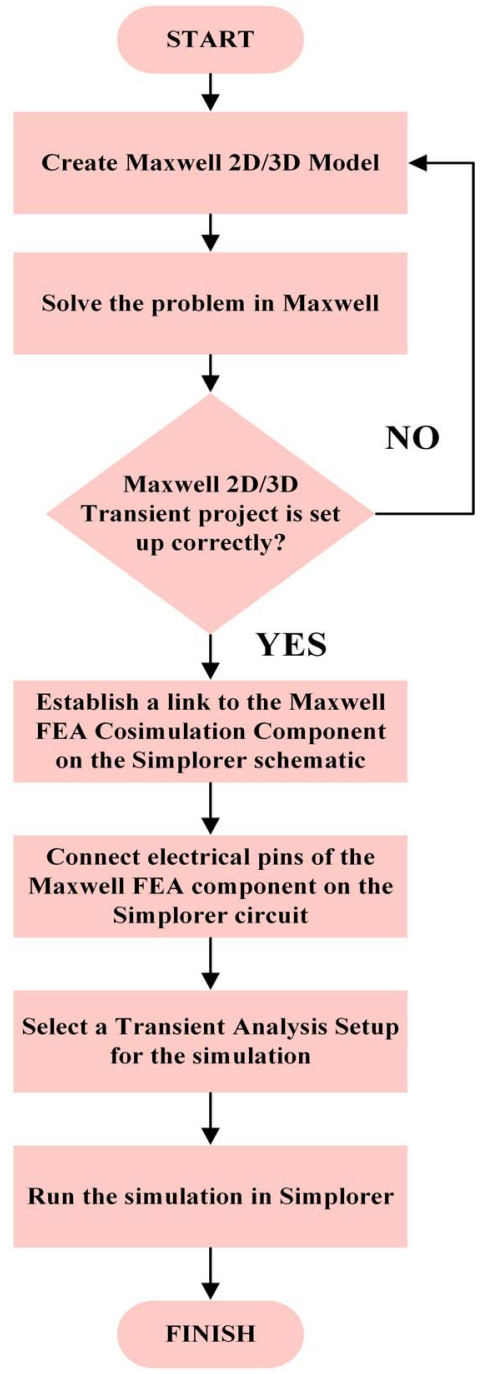

Figure 3. FEA co-simulation flowchart 


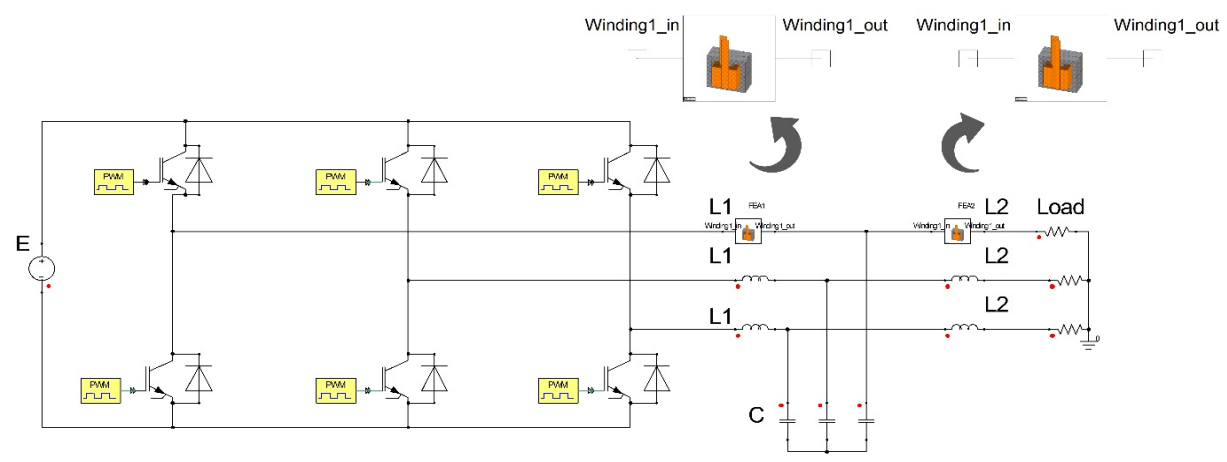

Figure 4. Inverter circuit on Simplorer schematic for the FEA co-simulation

Three-dimensional model of the inductor with 200 $\mu \mathrm{H}$ and $600 \mu \mathrm{H}$ inductance values is shown in Fig. 5 . Two pieces EE8020 cores are used to prevent saturation at rated inductor current, provide required current capacity. In simulation, $\mathrm{L}_{1}$ inductor is designed 37 turns and $600 \mu \mathrm{H}$. Besides, $\mathrm{L}_{2}$ inductor is designed 22 turns and $200 \mu \mathrm{H}$.

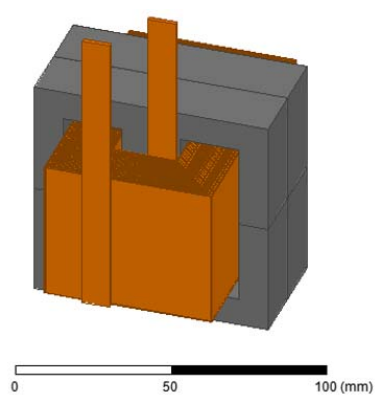

Figure 5. FEA model of the $\mathrm{L}_{1} / \mathrm{L}_{2}$ inductors

According to simulation results, electrical quantities for inductors and capacitor of the LCL filter for both three-level and two-level inverter are summarized in Table II. According to these values, it is seen that, better performance is obtained with threelevel inverter topology in terms of output voltage ripple, inductor total losses.

TABLE II. SIMULATION RESULTS ACCORDING TO THE INVERTER CIRCUIT TYPE

\begin{tabular}{|l|l|l|}
\hline \multirow{2}{*}{\multicolumn{1}{|c|}{ Parameters }} & \multicolumn{2}{c|}{ Inverter circuit type } \\
\cline { 2 - 3 } & \multicolumn{1}{c|}{ Two-level } & \multicolumn{1}{c|}{ Three-level } \\
\hline AC voltage ripple & $5.28 \mathrm{~V}$ & $3.32 \mathrm{~V}$ \\
\hline Reactor voltage $\left(\mathrm{L}_{1}\right)$ & $201.8 \mathrm{~V} \mathrm{rms}$ & $172.5 \mathrm{~V} \mathrm{rms}$ \\
\hline Reactor voltage $\left(\mathrm{L}_{2}\right)$ & $2.32 \mathrm{~V} \mathrm{rms}$ & $3.24 \mathrm{~V} \mathrm{rms}$ \\
\hline Capacitor current & $3.5 \mathrm{~A} \mathrm{rms}$ & $4.2 \mathrm{~A} \mathrm{rms}$ \\
\hline Reactor core losses $\left(\mathrm{L}_{1}\right)$ & $25.8 \mathrm{~W} /$ phase & $10.3 \mathrm{~W} / \mathrm{phase}$ \\
\hline Reactor core losses $\left(\mathrm{L}_{2}\right)$ & $2.5 \mathrm{~W} / \mathrm{phase}$ & $1.8 \mathrm{~W} /$ phase \\
\hline Reactor winding losses $\left(\mathrm{L}_{1}\right)$ & $14.6 \mathrm{~W} / \mathrm{phase}$ & $13.8 \mathrm{~W} / \mathrm{phase}$ \\
\hline Reactor winding losses $\left(\mathrm{L}_{2}\right)$ & $5.8 \mathrm{~W} / \mathrm{ph}$ ase & $5.3 \mathrm{~W} / \mathrm{phase}$ \\
\hline Total Losses & $146.1 \mathrm{~W}$ & $93.6 \mathrm{~W}$ \\
\hline
\end{tabular}

The current and voltage waveforms of the inverter side inductor of the LCL filter $\left(\mathrm{L}_{1}\right)$ are shown in Fig.6. It is seen that in case of three-level inverter, the voltage induced on inductor is closer to the sinusoidal waveform and current ripples are lower. Thus, core losses of the inductor are lower for three-level inverter.

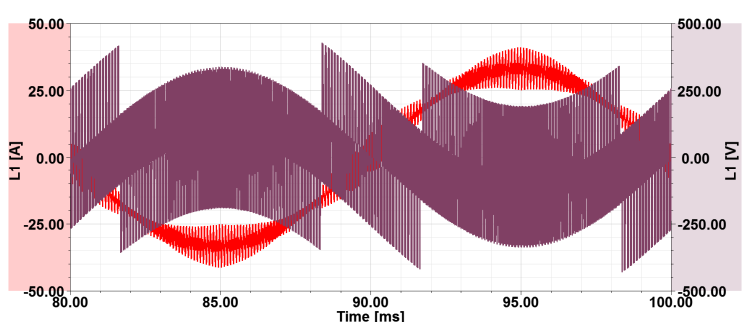

(a)

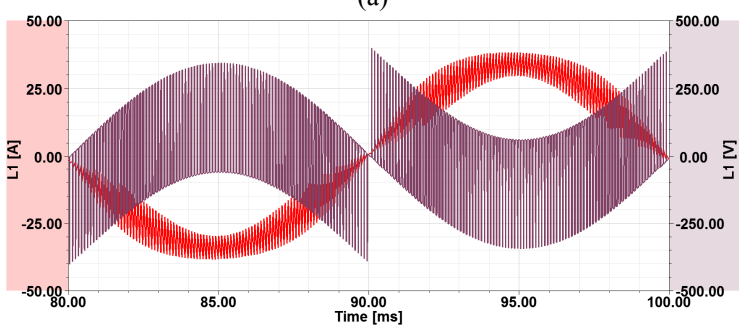

(b)

Figure 6. Voltage and current waveforms of $\mathrm{L}_{1}$, (a) two level inverter, (b) three level inverter

The current and voltage waveforms of the grid side inductor of the LCL filter $\left(\mathrm{L}_{2}\right)$ are shown in Fig.7. Here, rms value of the inductor for three-level inverter is higher than two-level inverter. These values are given in Table II comparatively.

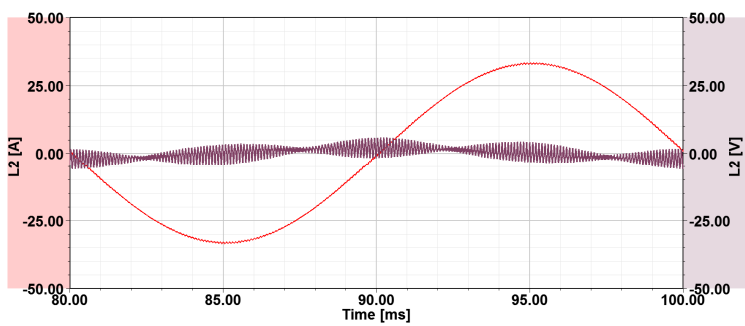

(a)

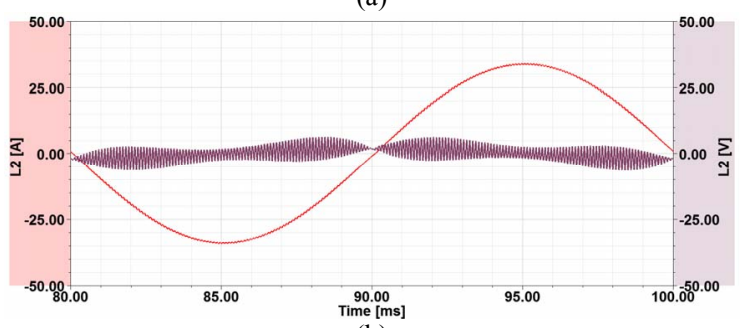

(b)

Figure 7. Voltage and current waveforms of $\mathrm{L}_{2}$, a) two-level inverter, b) three-level inverter 
The flux distributions in inductor cores are given in Fig.8. It is seen that, while flux value of $\mathrm{L}_{1}$ is about $0.5 \mathrm{~T}$, it is about $0.38 \mathrm{~T}$ in $\mathrm{L}_{2}$ inductor.

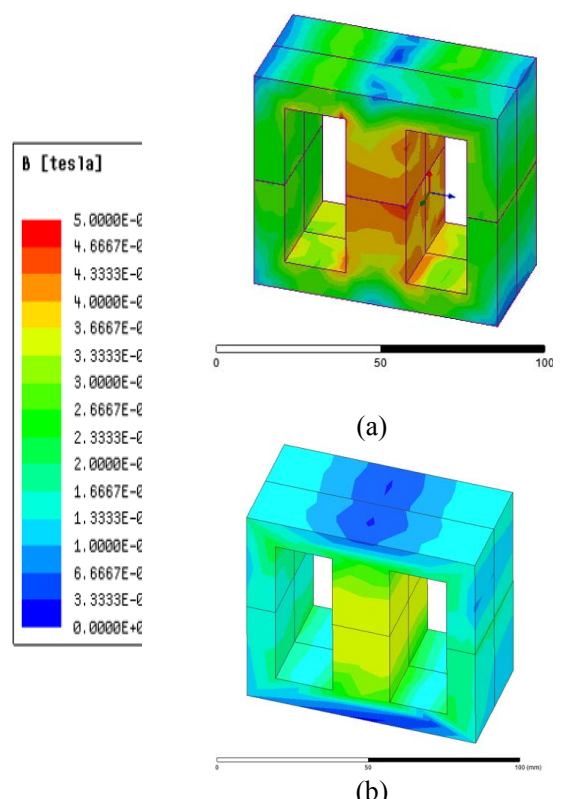

(b)

Figure 8. Flux distributions of $\mathrm{L}_{1}$ (a) and $\mathrm{L}_{2}$ (b) inductors

\section{CONCLUSION}

In this study, inductors of the LCL filter for an inverter at desired power level are designed and losses of designed inductors are analyzed with performed cosimulation studies with two-level and three-level inverter. The core losses of the inverter side inductor with three-level inverter is obtained as $10.3 \mathrm{~W}$, while it is $25.8 \mathrm{~W}$ with two-level inverter. Similar results are also obtained for grid side inverter. Finally, total core and winding losses of the LCL filter is obtained as 146.1 W and 93.6 W with two-level and three-level inverter, respectively. It is seen that more efficient operation can be obtained with multi-level inverters.

\section{REFERENCES}

[1] T. Hiratani, M. Namikawa, and Y. Nishina, "Reactor Characteristic Evaluation and Analysis Technologies of JFE Steel", JFE Technical Report, JFE Steel Corporation N0:21, pp.37-41, Mar. 2016.

[2] S. Balci, N. Altin, S. Özdemir, and I. Sefa, "FEM Based Parametric Analysis of AC Line Reactors", IEEE 4th International Conference on Power Engineering, Energy and Electrical Drives(POWERENG), pp.1328-1333, 2013.

[3] I. Sefa, S. Balci, and N. Altin, "Design of the AC Line Reactors With Finite Element Method", Journal of Polytechnic, Gazi Unv., 18 (4), pp.257-267, 2015.

[4] M.S. Rylko, K.J. Hartnett, J.G. Hayes, and M.G. Egan, "Magnetic Material Selection for High Power High Frequency Inductors in DC-DC Converters" IEEE TwentyFourth Annual Applied Power Electronics Conference and Exposition, pp.2043-2049, 2009.

[5] M. Mu, and F.C. Lee, "Comparison and selection of magnetic materials for coupled inductor used in interleaved three-level multi-phase DC-DC converters", IEEE Energy Conversion Congress and Exposition (ECCE), 20-24 Sept. 2015.

[6] S. Jayalath, D. Ongayo, and M. Hanif, "Modelling powder core inductors for passive filters in inverters using finite element analysis", Electronics Letters, Vol. 53 No. 3, pp.179181, 2nd February 2017.

[7] V.C. Valchev, T.P. Todorova, P.V. Yankov, and A. V. den Bossche, "Design considerations and loss analysis of DC chokes", IEEE19th International Symposium on Electrical Apparatus and Technologies (SIELA), 29 May-1 June 2016.

[8] A. K.Vaya, T. K. Parida, and S. K. Singh, "Efficiency improvement of a boost PFC converter using non-linear inductor", IEEE International Conference on Power Signals Control and Computations (EPSCICON), 6-11 Jan. 2014.

[9] B.G. You, J.-S. Kim, B.K. Lee, G.B. Choi, and D.W. Yoo, "Optimization of Powder Core Inductors of Buck-Boost Converters for Hybrid Electric Vehicles", Journal of Electrical Engineering \& Technology Vol. 6, No. 4, pp. 527534, 2011.

[10] M.K. Kazimierczuk, "High-frequency magnetic components", Second Edition, Wiley, Ohio, USA, 2014.

[11] C.W. T. McLyman, and A.P. Wagner, "Designing high frequency $\mathrm{AC}$ inductors using ferrite and molypermalloy powder cores (MPP)", IEEE Power Electronics Specialists Conference (ESA SP-230), 24-28 June 1985.

[12] J.D. Pollock, W. Lundquist, and C.R. Sullivan, "Predicting inductance roll-off with dc excitations", IEEE Energy Conversion Congress and Exposition (ECCE), 17-22 Sept. 2011.

[13] KoolMu26u EE8020 datasheet, https:/www.maginc.com/Media/Magnetics/Datasheets/00K8020E026.pdf

[14] Ansys-Simplorer Help, Release 18.0, December 2016. 